\title{
Extracting hospital hotel standards and criteria with a specialized hospital design approach
}

Extraer estándares y criterios de hoteles hospitalarios con un enfoque de diseño hospitalario especializado

Author:

Mohammad Shirvani ${ }^{1}$

Khatereh Heydarian ${ }^{2 *}$

\section{SCIENTIFIC RESEARCH}

How to cite this paper:

Shirvani M., Heydarian K., Extracting hospital hotel standards and criteria with a specialized hospital design approach, Iran . Innovaciencia 2020; 8 (1): 1-22. DOI: http:// dx.doi.org/10.15649/2346075X.1003

Reception date:

Received: 01 May 2020

Accepted: 01 August 2020

Published: 01 December 2020

Keywords:

Standard, Criteria, Hospital Hotel, Specialized Hospital

\section{ABSTRACT}

Background and Aim: Hospital design is based on the theoretical foundations of architecture and careful planning based on activities, equipment, standards and specific relationships between spaces. Applying the right standards and relationships between functions has a direct impact on the proper context of treatment. According to what has been said, the purpose of this study is to extract the standards and criteria of the hospital hotel with a specialized hospital design approach. Materials and Methods: The present study is a quantitative-qualitative method and based on this, first the qualitative evaluation of hospital environments in Kermanshah and then in the next stage, the obtained and presented standards have been proved. In order to evaluate the quality and evaluate the compatibility of the use of the standard environment, a semi-structured individual interview with hospital design specialists and researchers in this field and qualitative analysis of texts were used. The data obtained from the interviews were analyzed by coding method and in the next step, using the confirmatory factor analysis and laser software, the presented indicators were proved. Results and Results: In establishing hoteling standards in a specialized hospital, in addition to designing the initial physical spaces appropriate to the type of disease, three main questions were: Reasons for using the hospital hotel standard, the fit of the standards with the patient's needs and what these standards are. From the present study, we can point to the required standards in the field of hospital hotels with the approach of a specialized hospital with four basic indicators such as building and equipment, welfare services, human factors and functional factors. These are among the basic and emphasized standards that have been neglected.

1 Master's student, Department of Architecture, Arak Branch, Islamic Azad University, Arak, Iran.

mg900210@gmail.com

2* Master's degree, Department of Architecture, Kermanshah Branch, Islamic Azad University, Kermanshah, Iran. Corresponding author: Khatereh.heidarian@iauksh.ac.ir 


\section{INTRODUCTION}

The hospital hotel is a relatively new topic in architecture that, given the facilities and services it can provide to the public, needs to be felt in international architecture. The hospital hotel can provide support for family members and relatives and their stay with the patient as a positive factor in the course of the disease and accelerate the patient's recovery. This is possible due to the special design of the hospital, modeling of hotel architecture, etc [2]. Medical centers, especially hospitals, are a place for the interaction and coordination of various knowledge to combat incompatibilities and diseases that threaten human vitality. Artificial nature in which proper functional substrates should be provided well and even minimal design errors in design should be avoided. Therefore, in order to eliminate the shortcomings and non-repetition of past errors, as well as increase the information resources of engineers, it is very necessary and important to develop a hospital planning and design [3]. What is of particular importance in this type of medical service today is the strong desire of developing countries to enter this highly competitive field [4]. Health care services are one of the most important urban infrastructures. Hospital planning and design requires a comprehensive process in which architectural spaces, equipment, mechanical and electrical facilities are considered simultaneously and in one piece so that functional cohesion can be achieved in the hospital.

Hospitals, like an industrial unit, are made up of factors of production such as capital, manpower, technology, and management. Medicine and the training of skilled workers in the healthcare sector play a key role. Hospitals account for the bulk of health care costs in most countries, and there is ample evidence that such funding is being upgraded. According to the World Bank's extensive study of public hospitals, between 50 and 80 percent of public sector health resources in developing countries are consumed by hospitals. The World Health Organization (WHO) report confirms this, estimating that the share of hospitals in third world countries in government spending on health care is between 50 and 80 percent. In many countries, however, the budget spent on hospital services is never balanced by the actual production and provision of services.

This indicates that the correct and comprehensive knowledge of hospitals as the most important unit of health care providers is very important and efforts to improve the level of services of such centers, especially from the perspective of physical space, have a significant impact on improving quality. It will have services in the country's medical network.

\subsection{Research Background}

Clearly, the comfort of staying at the hotel does not make it possible for patients to stay in the hospital. Hospital designers can learn a lot from hotel designers in this regard. For example, hospital design can be inspired by nature and colors, or it can lead to information management. In addition, the hospital hotel is able to provide clinical medical services, and patients can recover. Due to the high cost of hospital beds, in addition to saving on patient costs, this issue can also compensate for the shortage of hospital beds [5]. Hospitals can be categorized in different ways and according to various indicators. Hospital by specialty: Hospitals can be divided into two categories: general and specialized hospitals. General hospitals are hospitals that provide specialized specialized services. Each public hospital has four wards for obstetrics, surgery, internal medicine and pediatrics.

Specialized hospitals are also referred to as hospitals that provide services in a specific specialty, such as cardiology. Educational hospitals are also a type of general or specialized hospitals in which treatment is accompanied by the training of medical and nursing students [6]. Hospital categories are examined and analyzed in terms of ownership:

1. Public hospital: includes any type of hospital that is built, supervised and managed by the government and based on the state budget. Hospitals covered by the universities of medical sciences, the Social Security Organization, the army, the Ministry of Petroleum, etc. are among the public hospitals. 
2. Private hospital: includes any type of hospital owned and managed by a natural or non-governmental legal entity and the result of the work belongs to the person, company or company. Of course, it is the government's responsibility to oversee and control their activities on a large scale.

3. Non-Profit Hospital (Charity): Includes any type of hospital owned and operated by a company, institution, charity or other organization, and no part of its net income legally belongs to any person or shareholder. It is not private. Such hospitals may be transferred to the government or run by a natural or non-governmental entity [7].
The shape of a hospital is strongly influenced by how it is accessed and the routes of travel; Therefore, in this case, it is decided to choose a shape such as a backbone with branches or to move the routes out of a central core in the form of rays. The arrangement of vertical communications within a hospital should be designed so that functional areas, care, treatment, provision, access to patients are prohibited, and the service yard is effectively connected and accessible [8] The following figure shows an example of hospital tourism space in the UAE and another example of a space suitable for the latest hospital hotel rules in terms of attracting tourism in Japan, which is one of the best equipped hospital spaces in accordance with world standards. Is mentioned:

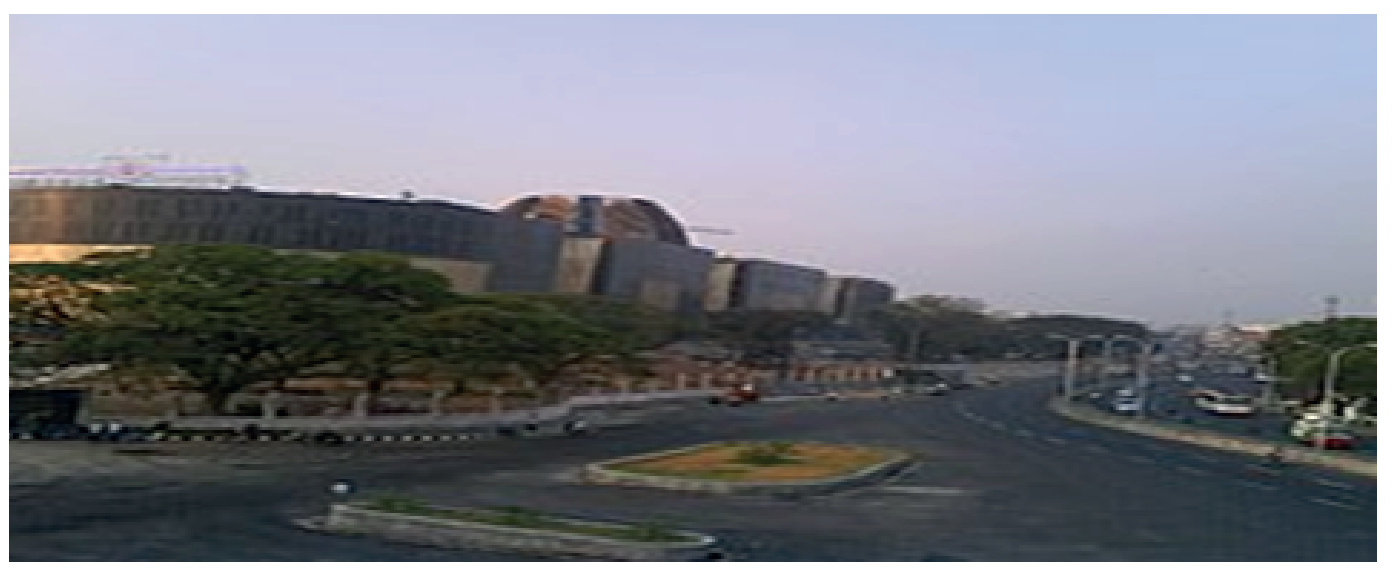

Figure 1: Hospital tourism space, UAE

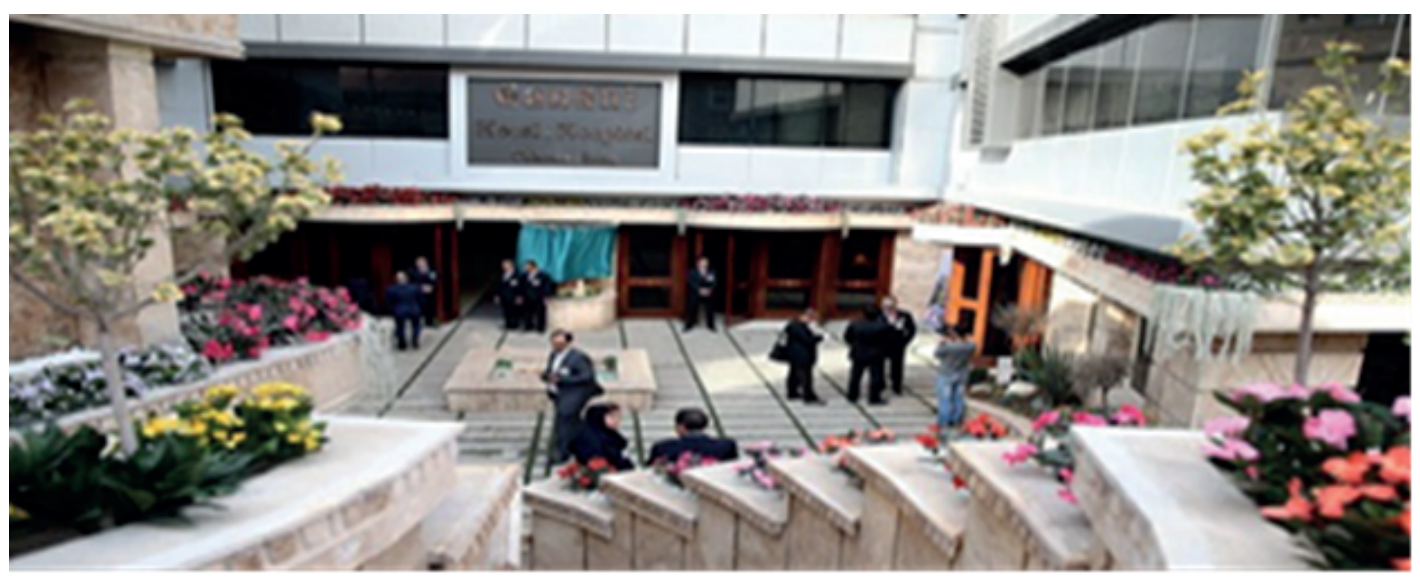

Figure 2: Health Tourism, Japan

Among developing countries, Iran is also one of the destinations that has a very high potential in this field of tourism [7]. In his research, Horitz (2007) acknowledges that by developing health tourism, citizens of developing countries have been provided with the services of receiving medical care and circumventing services; They are looking for reasonable prices and services that are tailored to their needs [8] in their research titled providing quality improvement modeling of hoteling services 
in public hospitals in Iran achieve these results in order to improve the hoteling situation of Iranian hospitals, while paying attention to 11 dimensions of special value including: physical dimension, Functional, economic, human, public and clinical welfare services, safety, culture, patient identification and patient guidance and care services need to be emphasized more in the functional dimension and in hoteling planning, the technical quality of healthoriented services should be examined.

Jabbari (2008) states that many governments are strengthening their hospital infrastructure, and paying more attention to media advertising and providing more facilities can lead to the growth and development of this important in the country. Mirzadeh et al. In their research entitled Hospital Hotel Design Basics with the approach of medical tourism (case study of Zahedan city) in the text of medical tourism or medical tourism as one of the dimensions of tourism helps sustainable development and dynamism of the country's economy. Given the lucrative nature of the industry, many developing and even developed countries are focusing on and planning for the industry. As we know, the city of Zahedan is located in the center of the southeastern region of Iran and connects the three countries of Iran, Afghanistan and Pakistan. Cheap and high quality medical services are among the medical attractions of Zahedan for foreigners and especially from the countries of origin. . In this way, it caused currency appreciation and, in a larger way, showed the face, civilization, science and knowledge of Iranians with a high penetration rate to the neighbors. In the domestic sector, it can be said that there is a shortage and lack of welfare and medical facilities in this region.

Medical and with the hypothesis that the design of residential suites in the hospital can solve the problems of traffic in the city and the challenges of family members who want to be with their patients during their stay in the hospital and most importantly in this way patients and their companions in It has been an environment that is very effective in the process of treatment and increasing the mental well-being of patients and their companions [8 ] The following images provide two examples of the most standard available spaces:

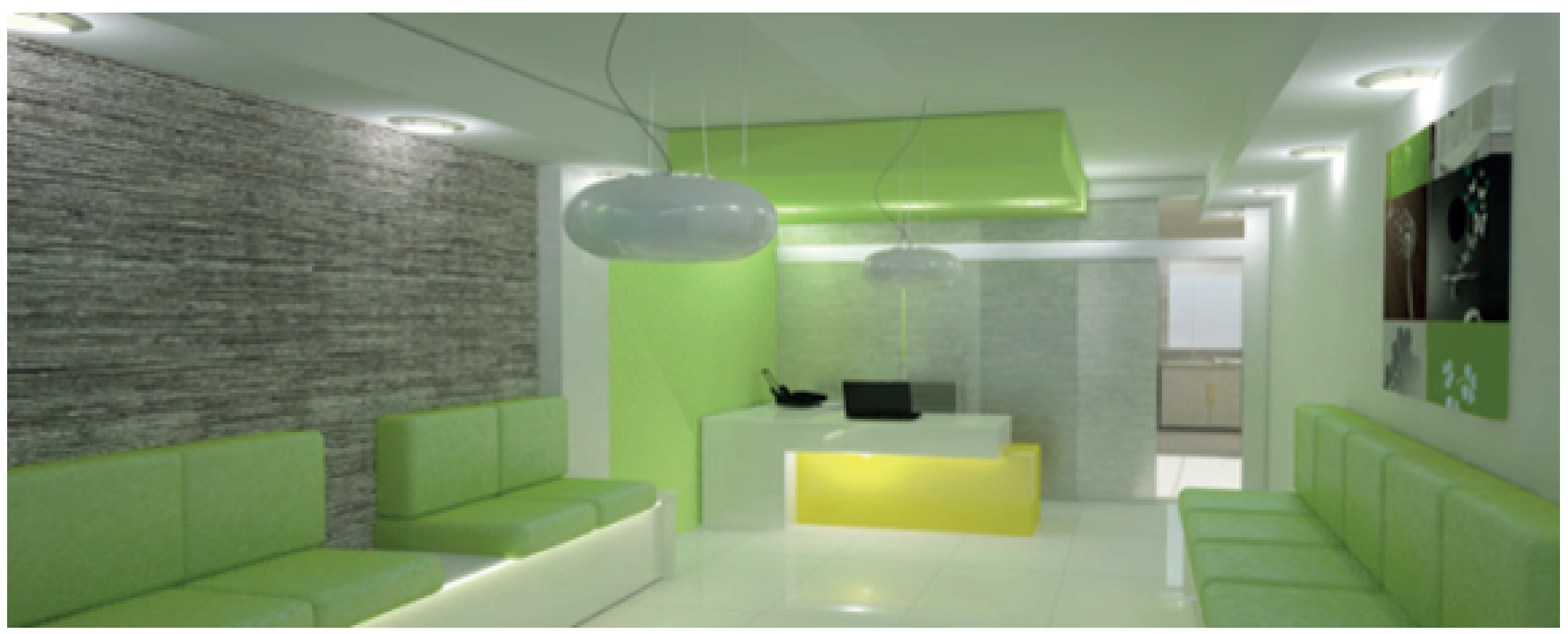

Figure 3: Hospital space standard 


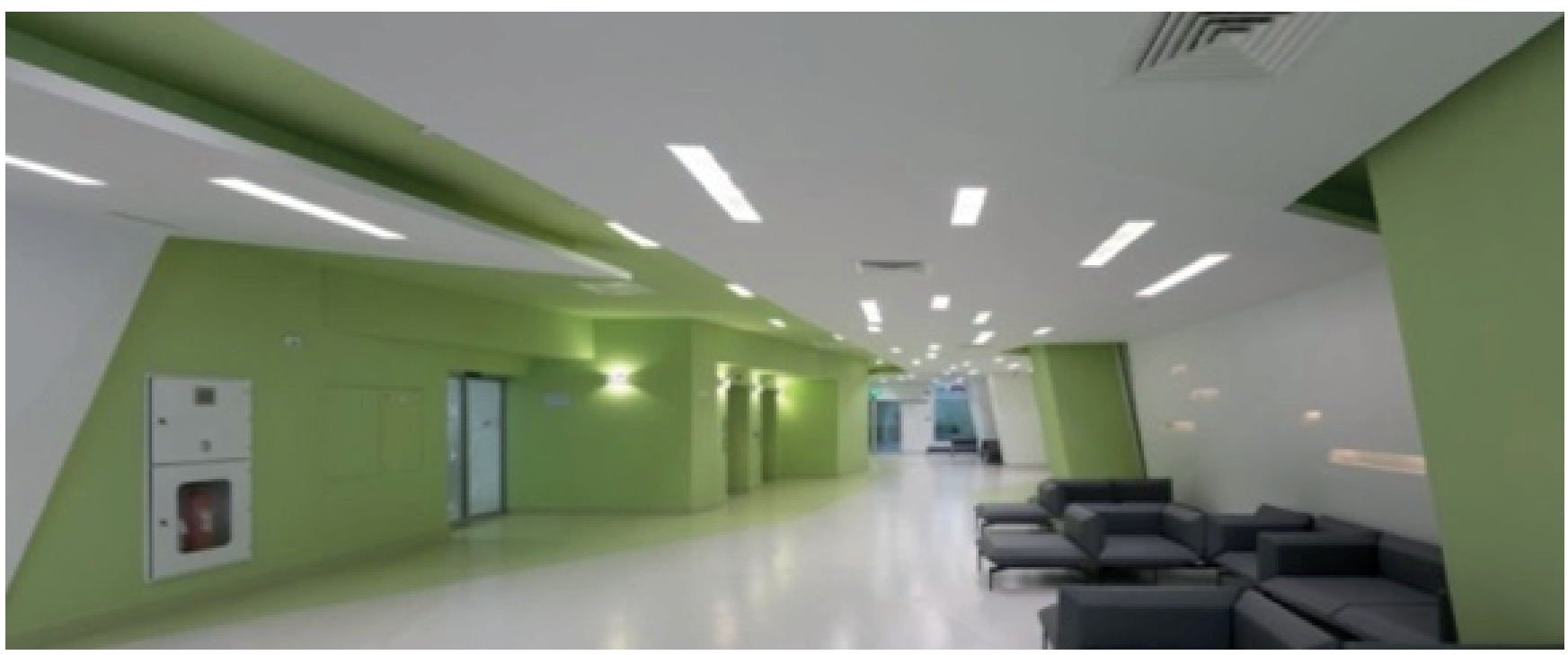

Figure 4: Hospital space standard

Badiei and Nasr (2015) in their research as strategies for designing hospital hotel architecture in Shiraz with an attitude on the interaction between the environment and users acknowledge that the design, implementation and layout of interior spaces in institutions with therapeutic-welfare use is always a problem. It has been important for interior architects and designers because the comfort and well-being of patients and their companions during treatment is very important, and we believe that focusing on treatment steps and other patient concerns will play a significant role in improving them as soon as possible.

Will have. The purpose of designing the architecture of such an environment is that the hospital hotel can support patients and families who are in a bad mood with fear and anxiety by creating favorable conditions. Spending long hours in therapeutic settings will usually have a positive effect on patients, visitors and staff, stressful experience of any effort to reduce this stress in the treatment process and increase the quality of these spaces, therefore, the architecture of such spaces causes Patients have a better view of the outside world as well as better communication with nurses or companions, and design and architecture play a decisive role in the process of treatment and improvement of patients in medical centers. Similar comments and case studies have been made in order to create and design the interior of the hospital hotel with an approach to the interaction between the environment and individuals in improving the quality of performance of medical-welfare spaces. Field surveys of existing spaces, collection of questionnaires from users and interviews with experts have been used, and the results indicate that the ideal design of the interior and exterior of hospital hotels due to various audiences such as patients, Patient companions, service and medical staff They are present in many times and are effective in relieving their stress and physical fatigue [10]

The following should be considered in the design of patients' rooms:

The following should be considered in the design of patients' rooms:

1- Considering natural light .. The view is that if the building is built in Tehran, light and south and east lights should be used.

2- Using artificial light at night by creating a false ceiling

3- Creating a suitable window for the patients' room, which depends on the climate of the region, and in mild weather, the window surfaces should not exceed $20 \%$ of the wall where the surface of the window is.

4- As far as possible, prevent direct sunlight 
from entering the patient's room, and this will be possible by creating a console, etc.

5- The windows should be opened slightly so as not to damage the air conditioning of the room and the windows should be equipped with a lock.
6- If the number of sick rooms in each floor is high, it is better to increase the number of corridors in that floor so that patients can be transferred to other corridors during a fire.

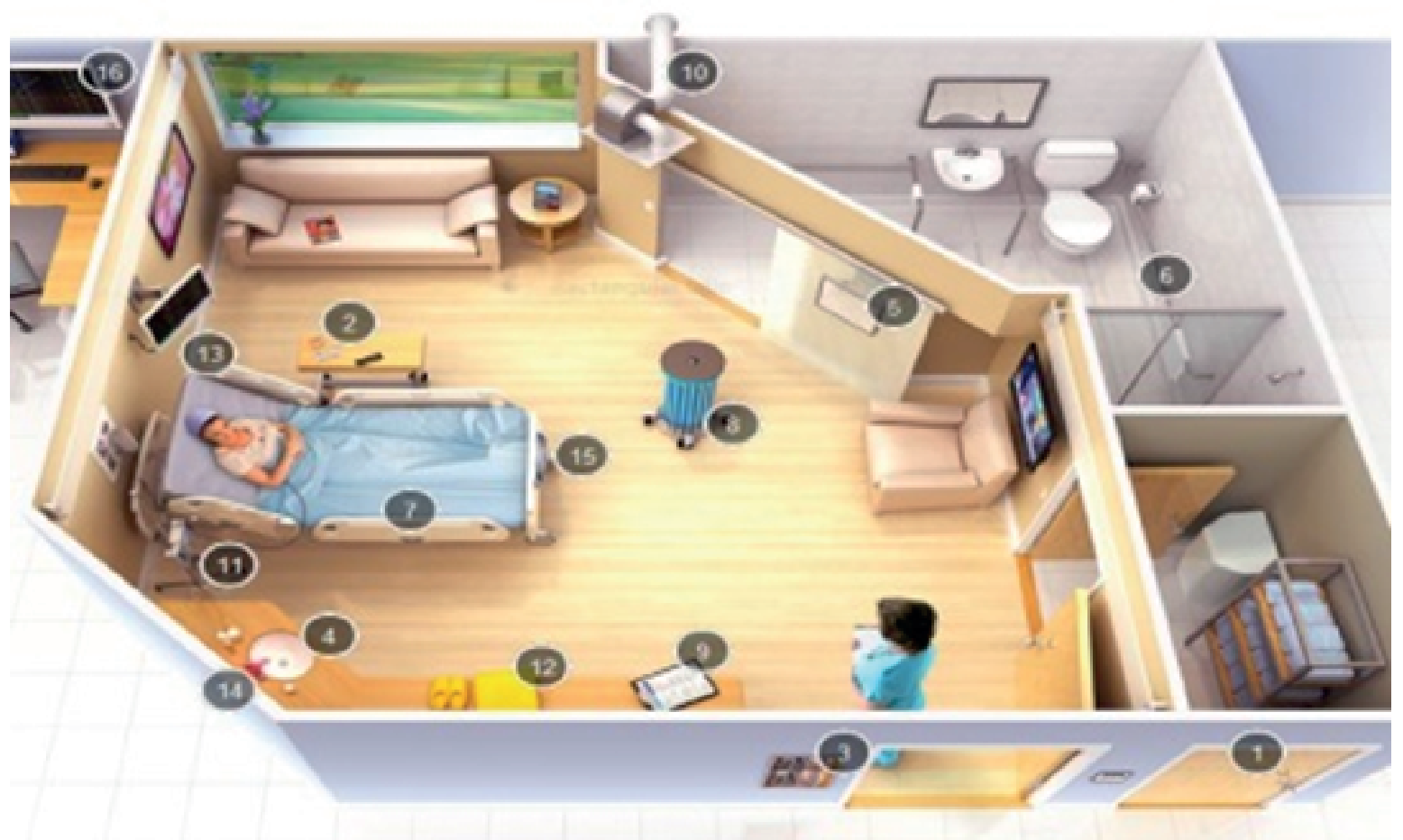

Figure 5: The room is an isolated bed

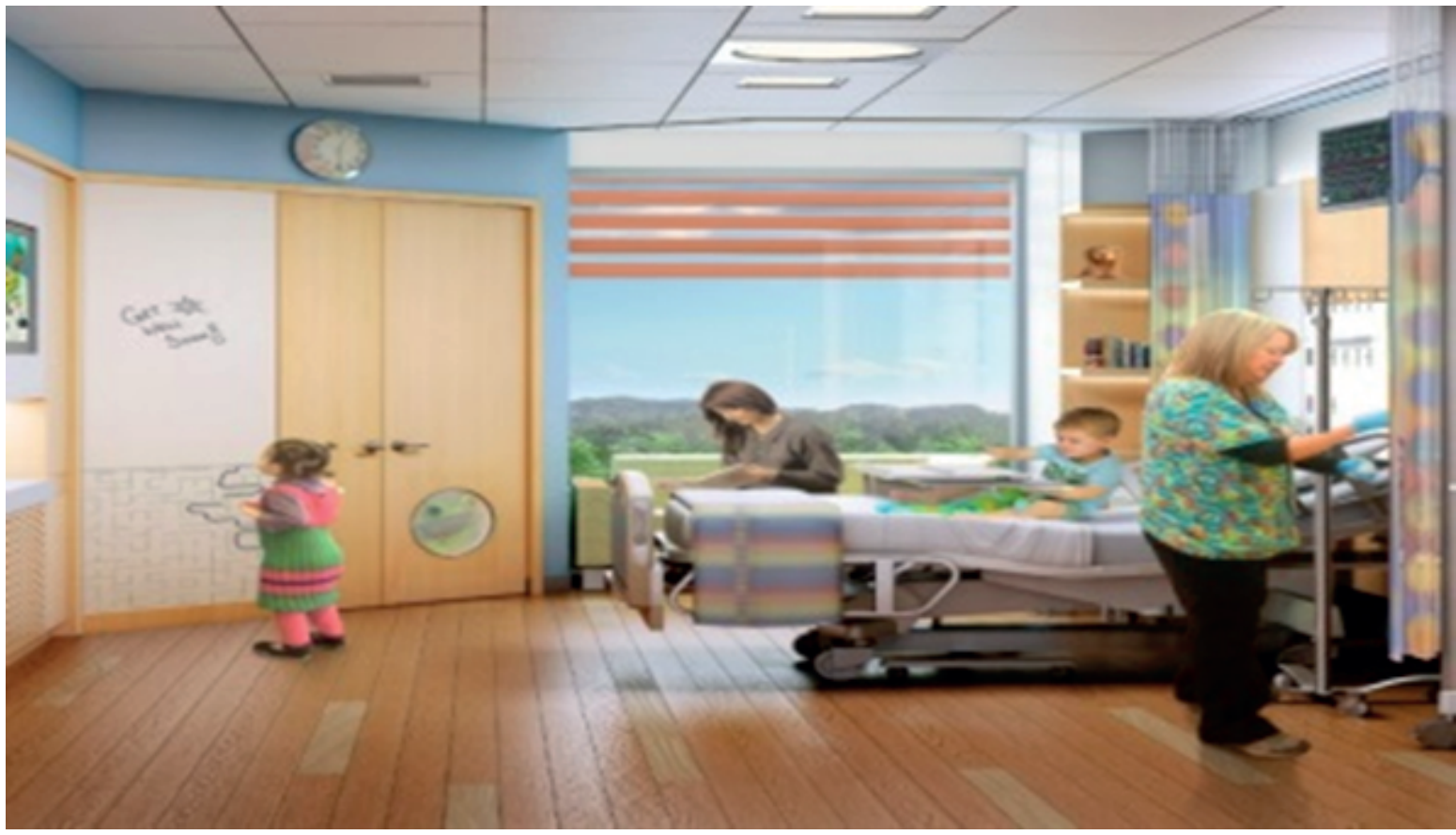

Figure 6: One-bedroom hospital room 


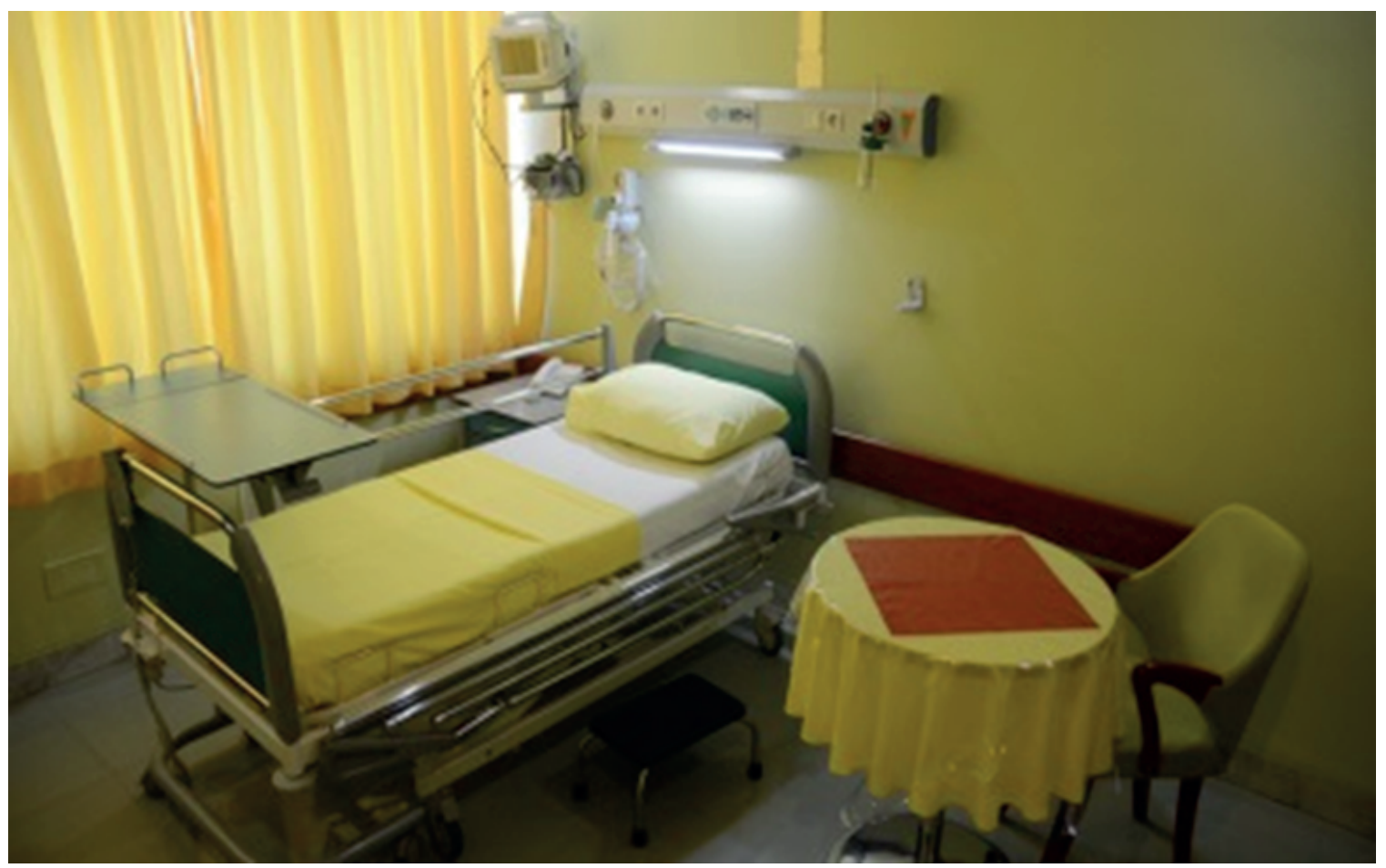

Figure 7: The patient's hospital room

Mansouri and Rasouli Dehbakari (2016) state that research and architectural design of hospital hospital in the form of an environmental therapeutic complex for the comfort of the patient's mental soul and patient and central companions to attract medical tourism is a basic principle and should be a fundamental step in the relationship. With the hospital hotel and effective factors removed, the integration of hotel and hospital duplication in a hospital hotel complex will improve the quality of treatment, accommodation and mental needs of patients and patients. In this regard, Aris and Karimi Consultant (1397) state that the relationship between art and urban space throughout history has benefited both phenomena. But the acceleration of the developments of the last century has caused challenges in the field of connection of art with urban spaces in our country, so that the art used in the city is more orderly and appealing than anything, popular, meaningful and consistent with the characteristics of space. In connection with the qualitative improvement of urban spaces, there are two main views on the phenomenon of urban art: "Art as a means of beautifying space" and "Art as a means of strengthening the audience's mental connection with urban space." In the second view, the main emphasis is on promoting the meaning of urban space through art. The connection between urban art and space in a deeper mental and semantic layer requires the discovery of the mechanism of the audience / actor's relationship with urban space and art, which is the main concern of this research.

According to what has been said, today's designed hospitals show a lack of things that are least compatible with the human needs of the twentieth century and are not able to respond to different and varied aspects, so to summarize the findings. The requirements for extracting the standards and criteria of the hospital hotel with the design approach of the specialized hospital need to be mentioned.

\subsection{Location and selection of hospital site}

Locating medical centers in its broadest sense has two stages:

First stage: In this stage, which deals with the issue of location with a macro perspective, in general, the construction site of the hospital is selected based on the country's divisions. Criteria such as morbidity rate, available facilities, population, human resources, 
macroeconomic-cultural and social conditions at the macro level, geographical location (roads and communications), comprehensive planning for classification and scope of specialized services and formation of specialized services referral network In the country, it is one of the determining factors in locating medical centers at this stage.

Second stage: This stage, which deals with the location of the location in more detail, is related to the selection of the exact location of the construction of the medical center within the limits set in the first stage (national divisions). This step involves physical planning that is related to urban regulations and zoning rules. At this stage, the criteria related to the characteristics of the centers and their external effects or the natural and physical characteristics of the city's lands play a decisive role in choosing a specific location for the relevant activity. In addition to these specifications, urban features will also affect the location process of these centers and their results and will create a specific deployment pattern. Since the first stage in locating medical centers is one of the major decisions and policies of the country's health system, it is out of the scope of this book, and in this section, more basic criteria and indicators related to the second stage of location are discussed:

Effective indicators and criteria in locating and selecting the hospital site: There are several factors and indicators that are effective in locating and determining the construction site of medical centers and should be carefully analyzed and analyzed during the study and planning phase. He reviewed the contract and applied it in the design of the medical center. First, the most basic indicators and criteria are named, and then a description of each will be provided:

1. Communication network and access

2. Neighborhood and neighborliness

3. Development plan and the principle of abundance

4. Infrastructure and infrastructure

5. Economic indicators and cost estimation principle

6. Cultural indicators and social psychology
7. Geographical location and climatic characteristics (climate wisdom)

8. Physical characteristics of lands

9. Land area and dimensions

10.Earth geometry

11.Types of pollution

12.Safety and passive defense Etc.[10]

Hospital grounds and spaces

In this regard, first of all, the components of these spaces should be recognized and introduced, and then the necessary standards should be expressed in this regard. The main elements in the perimeter of the main building of the hospital include the entrance and main entrance of the medical center, routes and passages, side and service buildings, green spaces and vegetation, parking lots, helipad, etc.

\subsection{Hospital building}

After discussing the issues related to planning and design in the field of location, the area and the surrounding areas of the hospital, the next step is to get acquainted with the hospital building. To examine the hospital building, first the hospital typology is determined in terms of form, then the common types of hospital building forms along with the disadvantages and advantages of each are discussed. After that, the effective factors in the location and formation of the hospital building, including climate, structural modulation of the building, the arrangement and placement of entrances, etc. are examined.

\subsection{Interior spaces}

Due to the fact that humans spend most of their time indoors, it is important to pay attention to design and architecture in the spaces that make up a place. In other words, the main part of any place from the architectural point of view is the interior spaces of that place. Because the maximum presence of each user in a building, of course, the interior spaces of that place is not the external environment. In medical centers, the provision of services in different categories, proper workflow and proper 
processes depend on the proper design of interior spaces. In addition, ensuring the comfort and wellbeing of all people, including patients, staff and clients, can be effective in improving productivity and service efficiency and speeding up the recovery process. Therefore, it is very important to pay attention to the category of interior space design.

Related topics related to indoor spaces in medical centers can be such as hospital infrastructure, location and internal communications, dimensions and internal proportions, elements and communication components, thinness requirements, opening requirements, light and brightness, color, insulation requirements $\mathrm{He}$ mentioned sound regulation, infection control, safety in indoor spaces and the requirements of the disabled in indoor spaces, and so on. Here are some tips to help you get started:

- Hospital infrastructure

- Location and internal communications

- Communication elements and their proportions

- Thinning requirements

- Light and brightness

- Color

- Voice

- Safety in indoor spaces

- Signs and signs [10]

Moving from a service-oriented approach to a healthoriented and hospitable approach that attracts people emotionally to the system is a factor that ultimately leads to an overall improvement in the quality of health care and customer loyalty to organizations. Will increase [11].
Hospitalization (hospitality services) means hospitality, hospitality and non-medical services and factors related to the patient's stay with the patients in the hospitals, which they experience from the time they enter the hospital until their departure, and the main causes of satisfaction or dissatisfaction. They are considered [12].

Emotional experience for patients is beyond the traditional model of service delivery, and this includes the analysis of data obtained from all five senses of the patient [13].

If it is a good experience, it is a connecting point that ensures that patients and their families will return when needed, and even recommend that health care organization to others [14].

Providing accommodation as a hotel-hospital will enable the patient's family to be accommodated with their patient during the treatment process and to witness the treatment process closely. This view will be very fruitful in multi-stage therapies. In the centers where the patient's companions' accommodation building is located, a separate entrance should be considered for it.

In the space space, hoteling is used for the equipment and devices that are used to hospitalize patients and provide accommodation services to them. This equipment also includes equipment related to the rest of doctors and staff. These include bedding, bedside tables, dining table, furniture, curtains, clothes hangers, and more. 
Table 1: Summary of research backgrounds

\begin{tabular}{|c|c|c|c|}
\hline Research method / collection tool & Research title & $\begin{array}{c}\text { Year of } \\
\text { publication }\end{array}$ & Author's name \\
\hline Question / Questionnaire & $\begin{array}{l}\text { The impact of hospital hospitality on therapeutic } \\
\text { tourism }\end{array}$ & 1395 & Mansouri et al \\
\hline $\begin{array}{l}\text { Qualified / semi-structured } \\
\text { interview }\end{array}$ & $\begin{array}{l}\text { Basics of hospital hotel design approach with } \\
\text { therapeutic tourism approach (case study of Zahedan } \\
\text { city; }\end{array}$ & 1395 & $\begin{array}{l}\text { Mirzadeh and } \\
\text { Faraj Elahi Rad }\end{array}$ \\
\hline $\begin{array}{l}\text { Qualified / semi-structured } \\
\text { interview }\end{array}$ & $\begin{array}{l}\text { Strategies for designing hospital hotel architecture in } \\
\text { Shiraz with an attitude on the interaction between the } \\
\text { environment and users }\end{array}$ & 1394 & Badiee et al \\
\hline Quality / interview, checklist & $\begin{array}{l}\text { Combining marketing and medical tourism } \\
\text { development in Shiraz }\end{array}$ & 1392 & Jabbari et al \\
\hline $\begin{array}{l}\text { Quite qualitative / interview } \\
\text { and questionnaire }\end{array}$ & $\begin{array}{l}\text { Providing a model to improve the quality of hoteling } \\
\text { services in Iranian public hospitals }\end{array}$ & 1390 & Shirzadi et al \\
\hline Quality / Interview & Emotional needs of patients & 2016 & Bon \\
\hline $\begin{array}{l}\text { Quite qualitative / semi- } \\
\text { structured interview, questionnaire }\end{array}$ & $\begin{array}{l}\text { The quality of hospital experiences: the impact of the } \\
\text { physical environment }\end{array}$ & 2016 & Divillin et al \\
\hline Question / Questionnaire & $\begin{array}{l}\text { The effect of ergonomic risk among employees of } \\
\text { central clothing distribution services in a hospital }\end{array}$ & 2012 & Sakus et al \\
\hline $\begin{array}{l}\text { Quite qualitative / questionnaire } \\
\text { and interview }\end{array}$ & $\begin{array}{l}\text { Provide a multidimensional framework for assessing } \\
\text { patient room settings }\end{array}$ & 2010 & Pat et al \\
\hline $\begin{array}{l}\text { Qualified / semi-structured } \\
\text { interview }\end{array}$ & Ideas for hotels and hospital hotels & 2009 & Burgan \\
\hline Quality / interview, checklist & Hospitality and services: guiding real change & 2009 & Corfu \\
\hline Question / Questionnaire & medical tourism & 2007 & Howitz \\
\hline $\begin{array}{l}\text { Quantitative Quality /Interview, } \\
\text { Questionnaire }\end{array}$ & $\begin{array}{l}\text { Multiple scales to measure consumer understanding of } \\
\text { service quality }\end{array}$ & 1988 & Parajman et al \\
\hline
\end{tabular}

\subsection{Research questions}

Given the above, the present study seeks to answer the question of what is the principle of extracting the standards and criteria of the hospital hotel with the approach of designing a specialized hospital?

1. What are the reasons for applying the hospital hotel standards and regulations?

2. What is the proportionality of the standards with the patient's needs in the existing hospital hotels?

3. What are the standards of a hospital hotel in a specialized hospital?

\section{6. research method}

Research is a regular practice that results in answers to the questions in question [15]
The research method should be selected according to its purpose and the nature of the problem under study [16]. According to the purpose of the present study, it has been included in the category of applied research, which has been performed using a combined or mixed exploratory research method. There are three points to consider in deciding why we have used the combined method: the research question, the researcher's personal experience, and the audience for which the report will be written.

Following the discussion, the research process was carried out in two stages: in the first stage, efforts were made to identify the desired situation by examining and studying the theoretical foundations of the proposed standards (first, we refer to library studies, which include reading And review of upstream documents, urban studies conducted by consulting companies, samples, related dissertations, internet search) using the opinion of experts as well 
as a review of resources and specialized studies, to design the desired situation. Therefore, at this stage, by using various techniques such as reviewing documents and also through interviews with hospital affairs experts, it was possible to identify the desired standard elements.

In the second stage, in order to provide the desired standards in the field of extraction, the most relevant standards in the field of specialized hospitals were defined. That included behavioral purpose, content, strategy, and evaluation. In order to explain the mentioned elements, different experiences that were obtained in the previous stages were used. In the third step, a validation step was performed to ensure the efficiency of the proposed standards. Although some qualitative researchers have discussed validity and validity, and the results of research have traditionally been related to quantitative research [17]. But the fact is that in qualitative research, the validity of data and findings is also a very important part of the research process [18]. Therefore, at first, $50 \%$ of the statistical sample was allocated to urban planning specialists and $50 \%$ to hospital specialists and experts. For this purpose, 24 specialists were selected using targeted chain type sampling method.

In order to sample individuals in qualitative research, instead of probabilistic sampling, intentional sampling or targeted sampling strategies are [19]. Be experts in the field of studies, as well as experts who have carried out scientific and research activities in the field of providing standards. Therefore, efforts have been made to select individuals whose opinions can be used to determine the validity of this study based on the professional knowledge and capabilities related to the present study.

Regarding the observance of standards and criteria related to the purpose of the present study, it should be noted:

- The development of a standard includes activities related to the creation of rules and principles that are recognized by a reliable source or public source or public agreement as the basis for measuring and comparing. These principles are the most pervasive or general of their kind, due to their conventional dimensions or form.
- Standardization is done by preparing a template and stabilizing it; But it must also have flexibility. That is, it should be able to be used in accordance with the needs and changes of environmental conditions and should be reviewed and updated as necessary.

The steps for developing a standard are as follows:

1. Select, review and confirm the topic

2. Determining the Secretary for Standardization and Communicating the Subject

3. Select source / resources

4. Selecting the members of the primary commission and inviting them to cooperate

5. Preparation of initial standard draft

6. Selecting the members of the technical commission and reviewing the initial draft of the standard in this commission

7. Selecting the members of the final commission and inviting them to review the initial draft and attend this commission

8. Review the final draft of the standard in the relevant international committee

9. Publication as the official standard of the country

Bistoon Specialized Hospital is the largest private hospital in Kermanshah province and Kermanshah city and has been studied as a statistical population. The construction of this hospital on a two-hectare land with an area of 18500 square meters began in 1994 and started operating in 1999. It should be noted that in the design of the specialized hospital, the standard set of hospital planning and design has been compiled with the support of the Ministry of Health, Treatment and Medical Education with the support of the Office of Physical Resources Development and Civil Affairs. . Therefore, in this regard, the points and requirements provided should be considered by consultants, contractors and respected hospital design experts. Currently, Biston Specialized and Subspecialty Hospital, with 215 beds, is a general hospital with a wide range of medical coverage and is the most equipped private hospital in the west of the country, which aims to provide and maintain health in all diseases due to the presence of specialist doctors And the subspecialty provides 
services in all fields. Looking at the perspective and 10-year horizon of this hospital, it has obtained permission to increase the number of hospital beds from Kermanshah University of Medical Sciences to 260 beds.

To analyze the qualitative data that the researcher has collected in different ways (careful study of theoretical foundations and previous research and conducting semi-structured interviews), first codify these data (open, central, selected) and classify them as Tables or charts are shown [20].

Therefore, due to the nature of the research topic in the qualitative stage, the method of data analysis was analytical-inferential. In other words, the method of data and qualitative information analysis was analytical and perceptual description of qualitative data, interpretation and theoretical inference, which in order to ensure the implementation of research, the process of conducting research, analysis, interpretation, inference and inference and findings by professors. The guide and consultant were reviewed and their comments were used to correct the work.

Finally, by encoding all the interviews, it reached the categories that provided the basis for the final analysis to answer the research questions. In this study, the process of implementing the data processing theory based on the most famous existing approach, namely the systematic approach of Strauss and Corbyn, has been used which includes data coding (including open, central and selective coding) [21] Interviews were conducted during the leisure time of the participants and in an environment free of any disturbing factors. The principle of confidentiality and confidentiality of information was observed in all stages of the research. Interviews ranged from 30 to 40 minutes. The following figure summarizes the study method.
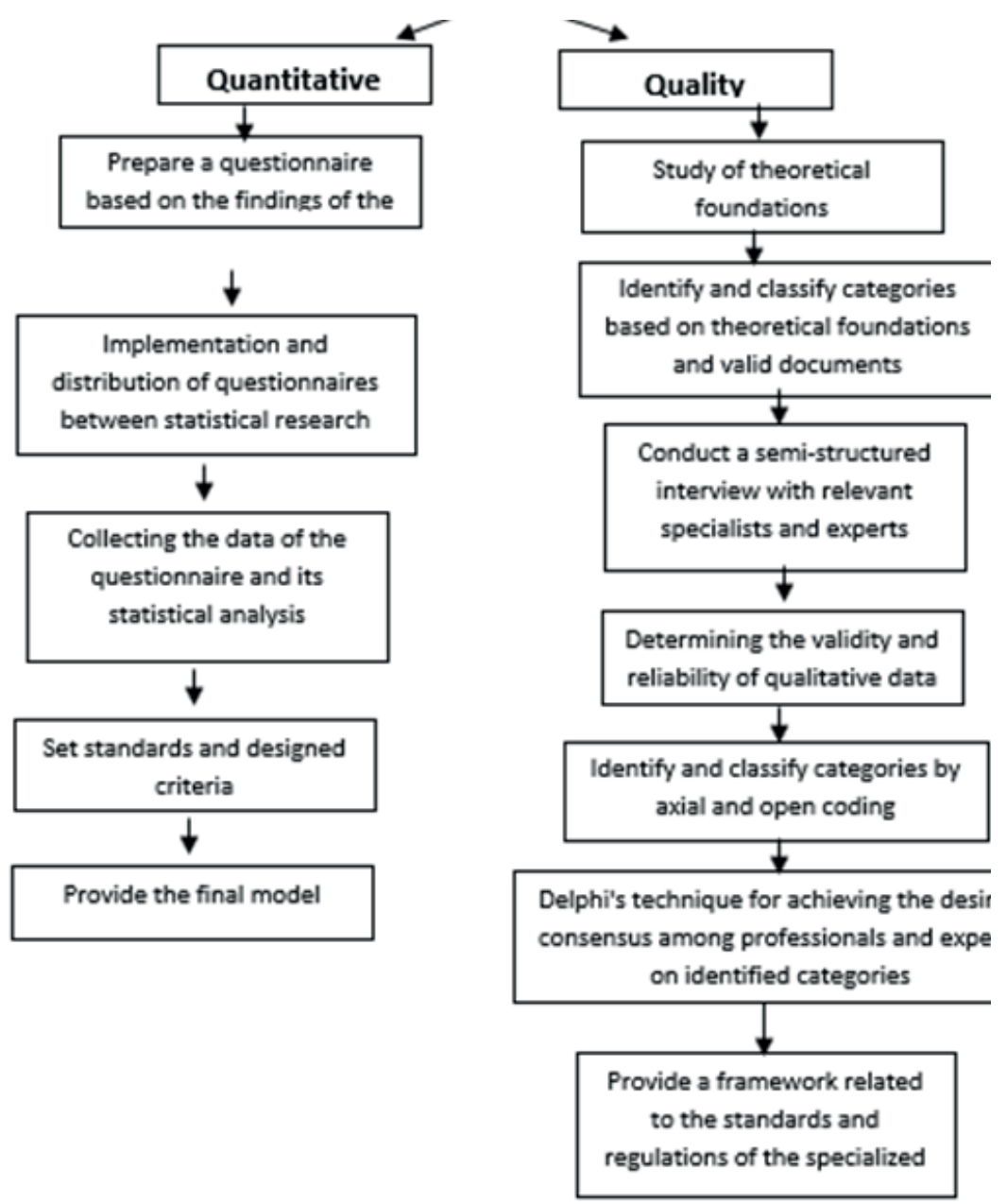

Chart 1: Steps to perform a combined exploratory method 


\section{RESEARCH FINDINGS}

The data collected from the interview with the participants in the study and during the in-depth and in-depth interview were analyzed in three stages (open coding, central coding, selective coding), which are presented according to the following research questions. . In line with the research questions, several questions were asked of the participants about the hospital hotel standards in the specialized hospital, the participants answered different questions in the interview.

In this study, 24 experts in urban planning issues and hospital affairs designer and researchers in this field were interviewed.

\subsection{Qualitative Question Results:}

1. What are the reasons for applying the hospital hotel standards and regulations?

1. What are the reasons for applying the hospital hotel standards and regulations?

Due to the existing theoretical foundations of the hospital hotel, it can provide the possibility of accompanying family members and relatives and their stay with the patient as a positive factor in the process of the disease and accelerate the patient's recovery. This is possible due to the special design of the hospital, modeling of hotel architecture, etc. [22]

Design and architecture play a decisive role in the process of treatment and improvement of patients in medical [23]

According to the content analysis of the answers given to the interviewees, factors such as:

- Dissatisfaction of patients and companions, disorder and chaos in visits and visits of clients remind the need to pay attention to a relaxing and well-equipped environment according to the sensitive conditions of patients and the need for therapeutic space.
- Spending long hours in medical settings, usually for patients, visitors and staff, stressful experience of any effort to reduce this stress will have a positive effect on the treatment process and increase the quality of these spaces, therefore, the architecture of such spaces will cause Patients have a better view of the outside world as well as better communication with nurses or companions.

- Proper and comprehensive knowledge of hospitals as the most important unit providing medical services is very important and efforts to improve the level of services of such centers, especially from the perspective of physical space, will have a significant impact on improving the quality of services in the country's health network.

- The hospital hotel can support patients and families who are in a bad mood with fear and anxiety by creating favorable conditions.

- Hospitals account for the bulk of health care costs in most countries, and there is ample evidence that such resources are available for promotion.

- Cheapness and high quality of hospital hotel services is one of the medical attractions, which is one of the main reasons for many developed countries. Developing countries (especially Iran, which has a favorable climate and manpower) can differentiate themselves by building such centers to increase and increase medical services in the region and the world.

- Architectural design of hospital hospital in the form of an environmental treatment complex for the comfort of the patient's mental soul and patient and central companions to attract medical tourism is a basic principle and a fundamental step should be taken in relation to hospital hospital and strengthening effective factors.

It shows the need to pay attention to the provision of standards and regulations in this field. 
Table 2: Coding related to the reasons for applying the standards and criteria of the hospital hotel

\begin{tabular}{|c|c|c|c|}
\hline $\begin{array}{l}\text { Selective } \\
\text { coding }\end{array}$ & Axial coding & Open coding & Question \\
\hline $\begin{array}{l}\text {-Extending } \\
\text { the quality } \\
\text { level of } \\
\text { services } \\
\text { - Acquiring } \\
\text { customer } \\
\text { satisfaction }\end{array}$ & $\begin{array}{l}\text { - Paying attention to the } \\
\text { changed needs of modern } \\
\text { humans } \\
\text {-Marketing and customer } \\
\text { orientation } \\
\text {-Increased satisfaction } \\
\text { - Paying attention to } \\
\text { hospitalization to be more } \\
\text { in line with the mental and } \\
\text { psychological conditions } \\
\text { of patients and the } \\
\text { environment }\end{array}$ & $\begin{array}{l}\text { - In the field of competition in the healthcare market, } \\
\text { meeting the needs of customers is of paramount } \\
\text { importance } \\
\text {-In the current era, it is not possible to provide services } \\
\text { only by relying on the quality of medical and nursing } \\
\text { services } \\
\text { - The main competition in providing hotel services and } \\
\text { amenities designed for the patient and accompanying } \\
\text { - Paying attention to the mental and psychological needs } \\
\text { of patients in hospital conditions; It is beyond the control } \\
\text { of doctors, nurses and the organizational climate } \\
\text { - Paying attention to marketing principles and techniques }\end{array}$ & $\begin{array}{l}\text { 1. What are the } \\
\text { reasons for applying } \\
\text { the hospital's hotel } \\
\text { standards and } \\
\text { regulations? }\end{array}$ \\
\hline
\end{tabular}

2. What is the proportionality of the standards with the patient's needs in the existing hospital hotels?

The integration of hotel and hospital use in a hospital hotel complex improves the quality of treatment, accommodation and mental needs of patients and their companions [24].

. Considering the existing theoretical foundations, the acceleration of the developments of the last century has caused challenges in the field of connection of art with urban spaces in our country, so that the art used in the city is more of a commanding and appealing nature than a popular one. With the characteristics of [25].

The hospital hotel considers the stay of the patient and the patient in the hospital from the moment of entering the hospital until the time of departure and by providing their needs in different types that are within the scope of welfare and medical duties, it provides them with satisfaction [26].

- Hospital planning and design requires a comprehensive process in which architectural spaces, equipment, mechanical and electrical facilities are considered simultaneously and in one piece so that functional cohesion can be achieved in the hospital. The shift from a purely service-oriented approach in the health care system to a customer-centric and hospitable approach that emotionally engages the system is a factor that ultimately leads to an overall improvement in the quality of health care and customer loyalty to organizations. Will increase [27]. Citizens of developing countries are provided with medical care and services; They are looking for reasonable prices and services that are tailored to their needs [28]. How to design, implement and arrange interior spaces in institutions with therapeuticwelfare use has always been an important issue for architects and interior designers [29]. According to the content analysis of the answers given to the interviewees, factors such as:

- Today's designed hospitals have little to do with the human needs of the twentieth century, and in practice they have not been able to meet the satisfaction of their customers who have different and diverse needs.

- Hospitals, like an industrial unit, are made up of production factors such as capital, manpower, technology and management, and using special facilities to produce products called ,preserving, restoring and promoting the physical and mental health of the community, as well as Medical research and the training of skilled workers in the healthcare sector play a key role.

- Obviously, the feeling of comfort that staying in a hotel gives patients, staying in the hospital can not create. Hospital designers can learn a lot from hotel designers in this regard. For example, hospital design can be inspired by nature and colors, or it can lead to information management. In addition, the hospital hotel is able to provide clinical medical services, and patients can recover.

- Paying more attention to media advertisements and providing more facilities can lead to the growth and development of this important issue in the country. has it. 
- The comfort and well-being of patients and their companions during treatment is very important, and we believe that focusing on the treatment process and addressing other patients' concerns will play a significant role in improving them as soon as possible. Unfortunately, we are witnessing a lot of negligence and heterogeneity due to the important impact of structures on the human psyche.

The level of compliance of standards with the patient's needs in the hotel indicates the existing hospitals.

Table 3: Coding related to the fit of standards with the patient's needs in the hospital hotel

\begin{tabular}{|c|c|c|c|}
\hline $\begin{array}{l}\text { Selective } \\
\text { coding }\end{array}$ & Axial coding & Open coding & Question \\
\hline $\begin{array}{l}\text { - System } \\
\text { clutter } \\
\text { - Inadequate } \\
\text { composition } \\
\text { of personnel } \\
\text {-Lack of } \\
\text { physical space } \\
\text {-Environment } \\
\text { al tensions }\end{array}$ & $\begin{array}{l}\text { - Dissatisfaction with } \\
\text { amenities such as physical } \\
\text { space, ease of travel, meals, } \\
\text { quick response } \\
\text { - Lack of satisfaction with } \\
\text { the appearance of the } \\
\text { hospital } \\
\text { - Lack of satisfaction with } \\
\text { the behaviors and attitudes } \\
\text { of the staff }\end{array}$ & $\begin{array}{l}\text { - Lack of creating a sense of satisfaction and desirability in } \\
\text { patients and companions } \\
\text { - The amount of certain indicators and the inconsistency } \\
\text { of the defined criteria of patients } \\
\text { - Lack of satisfaction with the service and welfare } \\
\text { facilities } \\
\text { - Lack of a sense of comfort and harmony with the } \\
\text { environment to create more effective conditions for } \\
\text { mental stability and treatment } \\
\text { - The existence of unrest and intolerance of the existing } \\
\text { environment }\end{array}$ & $\begin{array}{l}\text { 2. What is the } \\
\text { proportionality of the } \\
\text { standards with the } \\
\text { patient's needs in the } \\
\text { existing hospital } \\
\text { hotels? }\end{array}$ \\
\hline
\end{tabular}

3. What are the standards of a hospital hotel in a specialized hospital?

Considering the existing theoretical foundations in order to improve the hoteling situation of Iranian hospitals, while paying attention to 11 dimensions of special value including: physical, functional, economic, human, public and clinical welfare services, safety, cultural, patient identification and patient guidance and services Care should be taken to emphasize the functional dimension and to evaluate the technical quality of health-oriented services in hoteling planning [7]

In order to eliminate the shortcomings and not repeat the mistakes of the past, as well as increase the information resources of engineers, it is very necessary and important to develop a hospital planning and design standard [3]. Ideal interior and exterior design of hospital hotels Due to various audiences such as patients, patient companions, service and medical staff who have been present for a long time, it is effective in calming down their mental stress and physical fatigue [30].
Emotional experience for patients is beyond the traditional model of service delivery, and this includes the analysis of data obtained from all five senses of the patient [31].

This will remind us of the need to pay attention to all aspects of human existence. Important Dimensions in Hotel Design Specialized Hospital:

- The path of guests, equipment and staff should be separate. The effective width of stairs and footpaths should not be less than 50 meters.

- For each room, 6 square meters of corridor space with a width of 1.50 to 1.80 meters is required.

- The elevator shaft should be large enough to accommodate a bed and two that have the exact dimensions of the elevator: $1.20 \times 90 \mathrm{~m}$.

- The caretaker department of each floor is organized along the corridors leading to the guest room.

- To increase efficiency, it is better to shorten the paths between the kitchen, food delivery and restaurant as short as possible.

- Restaurants and buffets include banquet spaces that require a satellite-shaped kitchen near each restaurant and banquet room, and there are reception areas in the guest room on each floor.

- In hotel kitchens, medium-sized hospitals require one square meter of space per patient. This size for hotels in large hospitals reaches 1.2 square meters. 
- Public hotel spaces (including: foyer, dining and drinking areas, meeting space) and back space (including: kitchen, laundry and service space) that will be estimated according to the amount and volume of the patient and companions.

The design of residential suites in the hospital can solve the problems of traffic in the city and the challenges of family members who want to be with their patients during their stay in the hospital, and most importantly, patients and their companions in an environment where The process of reatment and increasing the psychological well-being of the patient and his companions is very [32].

The arrangement of vertical communications within a hospital should be designed so that the functional areas, care, treatment, provision, access to patients denied access, and the service yard are effectively interconnected and available [33]. According to the content analysis of the answers given to the interviewees, factors such as:

- To check the hospital building of the hospital, first the typology of the hospital in terms of the form is determined, then the common forms of the hospital building along with the disadvantages and advantages of each are discussed. After that, the effective factors in the location and formation of the hospital building are examined in accordance with the type of patient and companions, including climate, structural modulation of the building, how to arrange and place the entrances, and so on.

- In medical centers, providing services in different categories, proper workflow and proper processes are subject to proper design of interior spaces. In addition, ensuring the comfort and well-being of all people, including patients, staff and clients, can be effective in improving productivity and service efficiency and speeding up the recovery process.

- Providing accommodation as a hotel-hospital will cause the patient's family to be accommodated with their patient during the treatment process and to witness the treatment process closely. This view will be very fruitful in multi-stage therapies. In the centers where the patient's companions' accommodation building is located, a separate entrance should be considered for it.

- In relation to hospital hotel space standards, such as hospital infrastructure, interior and communications infrastructure, dimensions and internal proportions, elements and communication components, thinness requirements, light and brightness, color, sound adjustment requirements, safety in spaces Interior and the requirements of the disabled in interior spaces, etc., pointed out that these cases are of special importance in combining specialized space with a comfortable environment.

- Man is inherently a perfectionist and beauty-loving creature, and paying attention to this existential trait, especially in times of illness and various diseases, according to his needs, will have tremendous effects on his morale and satisfaction. Therefore, paying attention to the beauty of the environment and the appropriateness of the art used in the building according to the type of disease are among the important standards.

- The shape of a hospital is strongly influenced by how it is accessed and the routes of travel; Therefore, in this case, it is decided to choose a shape such as a backbone with branches or to move the routes out of a central core in the form of rays.

- The things that should be considered in the design of a hospital hotel are: a) Considering natural light and the need for fresh air. B) Paying attention to the location of objects and coloring appropriate to the type of disease and .... C) Paying attention to the location of people passing by and the patient's position.

- Hoteling in the space dimension to the equipment and devices that are used to hospitalize patients and provide accommodation services to them. This equipment also includes equipment related to the rest of doctors and staff. These include bedding, bedside tables, dining table, furniture, curtains, clothes hangers, and more.

- Hospitality (hospitality services) experience hospitality and hospitality and related non-medical services and factors and is one of the main causes of their satisfaction or dissatisfaction.

The hospital's hotel standards are specialized in the hospital. 
Table 4: Coding of hospital hotel standards in a specialized hospital

\begin{tabular}{|c|c|c|c|}
\hline $\begin{array}{l}\text { Selective } \\
\text { coding }\end{array}$ & Axial coding & Open coding & Question \\
\hline $\begin{array}{l}\text { - } \\
\text { eonstruction, } \\
\text {-quipment } \\
\text {-welfare } \\
\text { Sevices } \\
\text {-Human } \\
\text { Factors } \\
\text {-Functional } \\
\text { factors }\end{array}$ & $\begin{array}{l}\text { - Lobby, decoration and } \\
\text { furniture, green space and } \\
\text { color scheme, facilities, } \\
\text { summoning system } \\
\text { - Restaurant, parking, } \\
\text { internet and computer } \\
\text { access, tranquility, mini } \\
\text { bar, laundry } \\
\text { - Personnel specializing in } \\
\text { ceremonies, services, } \\
\text { nutrition and counseling, } \\
\text { how to communicate } \\
\text { effectively with staff } \\
\text { - Employee motivation } \\
\text { system, financial } \\
\text { transparency, ease of } \\
\text { admission and clearance, } \\
\text { correct and timely } \\
\text { information a }\end{array}$ & $\begin{array}{l}\text { - Spaces required for specific patient companions } \\
\text { (infants, the elderly, ...) } \\
\text { - Proper vision, lobby, hallway, hot and varied healthy } \\
\text { food, air conditioning, hot and cold water in all floors, ... } \\
\text {-Specialized service manager in the field of providing } \\
\text { different patient services } \\
\text { - The presence of ceremonial experts, nutritionists, } \\
\text { religious counselors and psychologists } \\
\text { - Nurse summoning system, internet access, privacy and } \\
\text { privacy and ... } \\
\text { - Proper and timely information, diversity in the system } \\
\text { paid } \\
\text { - Uniform coating and coloring based on tasks affect how } \\
\text { effective communication is } \\
\text { - Geographical location and climatic characteristics - } \\
\text { Communication network and easy access } \\
\text {-Equipment and facilities } \\
\text {-Various and flexible services tailored to the needs of the } \\
\text { patient and his companions } \\
\text {-Services, cleaning and sanitation } \\
\text {-Patient nutrition } \\
\text {-Administrative work and turnover }\end{array}$ & $\begin{array}{l}\text { What are the } \\
\text { standards of a } \\
\text { hospital hotel in a } \\
\text { specialized hospital? }\end{array}$ \\
\hline
\end{tabular}

In this section, in order to confirm the obtained variables, the relevant questionnaire was set and the related variables remained from the point of view of experts. After confirming the validity by the experts and the reliability of the Cronbach's alpha coefficient method, the approved questionnaire was prepared in the form of 94 questions. At this stage, the questionnaire was distributed in a specialized hospital with 1035 patients and their families and health experts. The sample size was calculated based on the Cochran's formula with a 5\% error level of 280 people.

At this stage, structural equation modeling or multivariate analysis with possible variables has been used to investigate the relationships of variables. Verbal factor analysis is one of the oldest statistical methods used to investigate the relationship between possible variables (factors obtained) and observed variables (questions) and indicates the measurement model. With this approach, the acceptability of theoretical models in specific communities can be tested.

Researcher's questionnaire on building and equipment dimensions (lobby, decoration and furniture, green space and color scheme, facilities, summoning system, safety), welfare services (restaurant, parking, internet and computer access, environmental tranquility, mini bar, laundry), Human factors (staff of ceremonies, services, nutrition and counseling, effective communication of personnel, cultural issues), functional factors (employee motivation system, financial transparency, ease of admission and clearance, correct and timely information) with a range of five Liquor is considered. To measure reliability, the prototype included forty pre-test questionnaires. Then, using the data obtained from the questionnaire, Cronbach's alpha reliability coefficient was calculated, which is $0.81 \%$ for building indicators and equipment, respectively. $0.753 \%$ was obtained for welfare services, $0.760 \%$ for human beings, $70 \%$ for functional factors. These numbers indicate that the questionnaire is reliable and, in other words, reliable. Factor validity has been used to measure the validity of the questions.

Factor validity is a form of structural validity that is obtained through factor analysis [7]. In fact, it is necessary to use factor analysis in the branches in which the questionnaire and test are used and the variables are of the type we have today. 
At this stage, the normality of the data test was measured by the Clemo Grof-Smirnov test, and since the significance level of all variables was greater than 0.05 , we conclude that all variables follow the normal distribution. In the next step, because the data distribution was normal, Pearson correlation coefficient was used to investigate the correlation between the variables and the correlation coefficient between the variables was significant according to the obtained figures.

Table 5: Clemogroff-Smirnov test results to examine data compliance from normal distribution

\begin{tabular}{lll}
\hline Meaningful level & The amount of Smirnov-Clemogrov statistics & Variables \\
\hline 0.241 & 1,210 & Buildings and equipment \\
0.352 & 1,125 & welfare Sevices \\
0.167 & 1,137 & Human Factors \\
0.143 & 1,269 & Functional factors \\
\hline
\end{tabular}

Table 6: Pearson correlation coefficient

\begin{tabular}{llllll}
\hline $\mathbf{5}$ & $\mathbf{4}$ & $\mathbf{3}$ & $\mathbf{2}$ & $\mathbf{1}$ & Variables \\
\hline & & & 1 & 0.625 & Buildings and equipment \\
& & 1 & 0.637 & 0.530 & welfare Sevices \\
& 1 & 0.732 & 0.680 & 0.672 & Human Factors \\
1 & 0.590 & 0.767 & 0.619 & 0.536 & Functional factors \\
\hline
\end{tabular}

Based on the structural equation modeling method, one of the important features of which is the possibility of participation of latent variables, application of multiple sizes, possibility of error, adaptation of distributed assumptions and the ability to work with different types of data. So the model variables are classified into two categories, endogenous and exogenous, and are placed in the model. The definition of model variables was based on the necessary studies and research in previous research.

The factor structure of each variable was measured by Barlett's sample adequacy index test and the sphericality of the barrel test. Identification of latent factors determined the number of latent factors in terms of specific values and after announcing the appropriateness of the data collected with the model in each fit variable was confirmed.

Table 7: KMO-Bartlett test results

\begin{tabular}{lll}
\hline $\mathbf{0 . 7 7 9}$ & KMO sampling adequacy criterion \\
\hline 43,892 & Kai Dó \\
20 & Degrees of freedom & Bartlett's test \\
0.021 & Meaning level & \\
\hline
\end{tabular}

In the following, the structural equation model will be discussed in the standard estimation mode. Table 8 shows the coefficients of the effect of the variables.

Table 8: Investigating the relationship between variables using the structural equation model

\begin{tabular}{lll}
\hline Assuming the result & Significance level & Impact rate \\
\hline No rejection & $\mathbf{0 . 0 0 0}$ & 0.573 \\
No rejection & $\mathbf{0 . 0 1 1}$ & 0.671 \\
No rejection & $\mathbf{0 . 0 0 0}$ & 0.700 \\
No rejection & $\mathbf{0 . 0 3 3}$ & 0.717 \\
\hline
\end{tabular}


Table 9 shows the fit of the structural equation model.

Table 9: Characteristics of fitting structural equation models

\begin{tabular}{|c|c|c|c|}
\hline Index title & the amount of & Result & \\
\hline$\frac{x^{2}}{d f}$ & 2,714 & Do not reject the model & Excuse me \\
\hline RMSEA & 0.032 & Do not reject the model & $\begin{array}{l}\text { The root of the error is the average of the } \\
\text { approximation }\end{array}$ \\
\hline RMR & 0.290 & Do not reject the model & $\begin{array}{l}\text { The root of the average of the remaining } \\
\text { squares }\end{array}$ \\
\hline GFI & 0.943 & Do not reject the model & Good fit \\
\hline AGFI & 0.945 & Do not reject the model & Corrected fitness index \\
\hline NFI & 0.950 & Do not reject the model & Normal fit index (Bentler-Bont; \\
\hline CFI & 0.929 & Do not reject the model & Adaptive fit index \\
\hline IFI & 0.940 & Do not reject the model & Incremental fitness index \\
\hline
\end{tabular}

Based on the obtained results, it can be acknowledged that all the evaluation indicators of the above model are in this domain, and therefore the appropriateness of the data collected with the model is desirable.
Therefore, the suitability of the structural equation model is confirmed. In the following figure, the final model and its dimensions are presented:

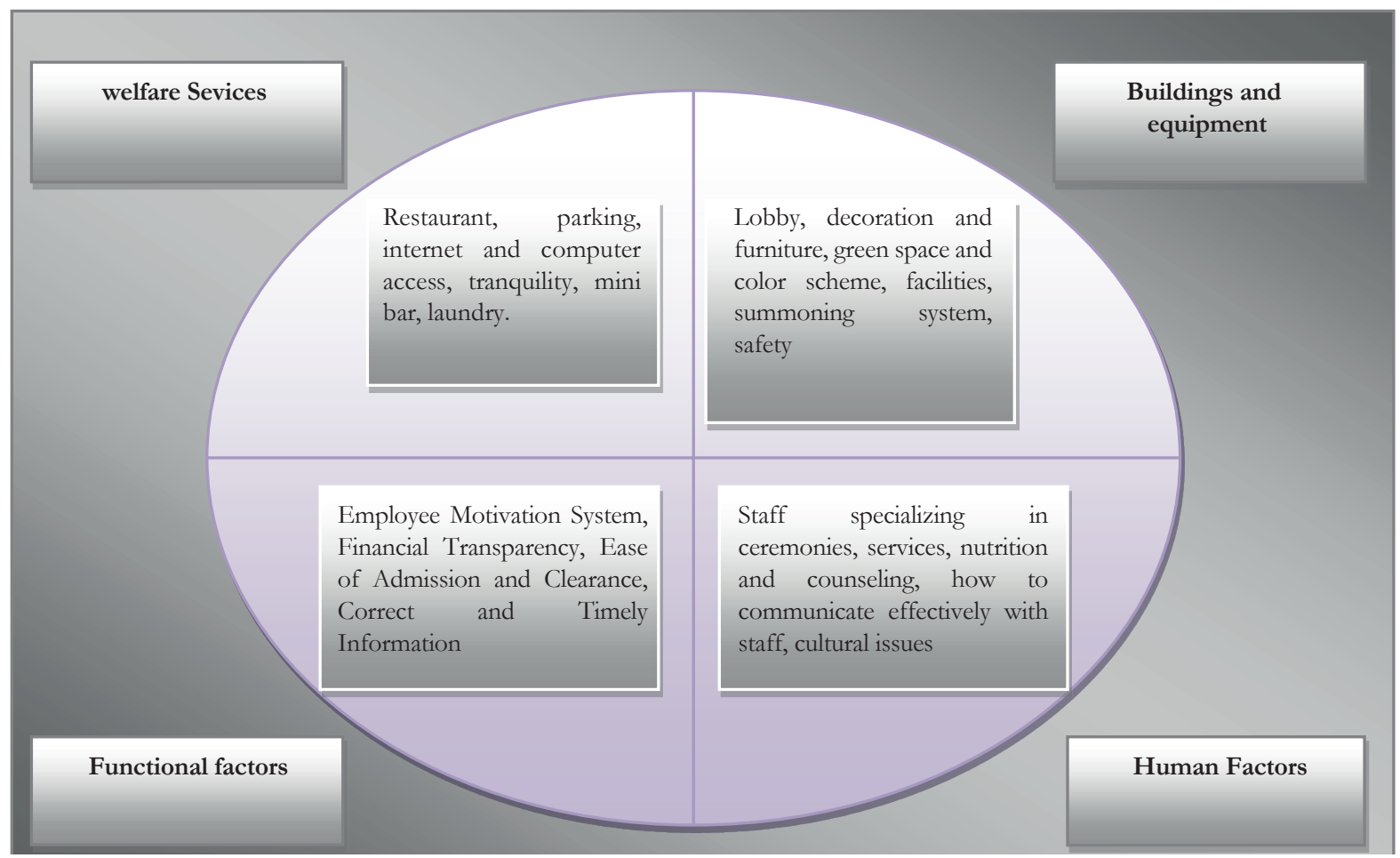

Figure 6: Dimensions of the final model of the rules and standards of the specialized hospital hotel 


\section{DISCUSSION}

Health is considered to be one of the most important and basic human needs, among which hospitals are an important arm of providing health services with specific and specific responsibilities and are known as the most important health centers. Improving the quality of services in service centers, including hospitals, is one of the important goals of sustainable development in the country. The main task of service providers is to meet real and tangible needs and to satisfy them. It is the patient's satisfaction that indicates the correct performance of the desired services in the hospital [13].

People not only want to treat the hospital as a medical center, but they also compare the hospital with a hotel in creating the environment, facilities, services and quality of accommodation [11].

Models have been implemented around the world, and in some hospitals, accommodation centers have been set up alongside a set of health services to make it easier for the patient or his companions. In some countries, this residence is for the patient and his companion, and in other countries, other people can use it[5].

Based on the findings of the qualitative stage, it is concluded that the existing beds are not sufficient for the standards and promotion and dissemination of criteria in the field of hotels of the studied hospitals. In this regard, the present study has considered the two scales of improving the quality level of services and gaining the satisfaction of clients (customers of the organization) as basic factors in relation to this important issue (Table 2). In terms of the fit of existing standards with the needs of patients to the hotel hospital, the four elements of system imbalance, inappropriate composition of staff, lack of physical space and environmental tensions are the main factors that indicate inconsistencies and incompatibility of components (Table 3). In the third part, which is the main part of the research, by presenting the standards, he pointed to four indicators with the titles of building and equipment, welfare services, human factors and functional factors, which are among the most important elements in providing standard hoteling (Table No. 4). Finally, with the approval of the presented model, according to the obtained indicators, it is stated that the mentioned model is presented.

In this regard, it should be noted that in Iran, despite the existence of appropriate capacities in the field of medicine, less investment has been established and expanded such collections with modern world standards.

Tahai has not been fully implemented as a hospital hotel, and there are serious flaws in one of the two parts of the hotel or hospital.

\section{RESEARCH SUGGESTIONS}

In the discussion of the hospital hotel, which has also been considered as an added value by many developed countries in the world, it should be noted that Iran has an effective infrastructure that is facing a lot of negligence. Today, hospital hoteling, at first glance, causes positive or negative views of patients towards medical centers, and since the initial knowledge is based on these welfare and biological services, it will be the basis for judging and selecting many clients. Items such as hospital cleaning, how employees provide services, nutrition, layout and beauty of the environment, patient room equipment, etc. can be easily identified. For this reason, the criterion for judging patients and their companions will be based on hospitalization of hospitals. In this regard, it is recommended that future research be based on many of the hospital's hotel promotion sub-scales, such as how employees talk and treat patients and their companions, improving environmental intelligence, emphasizing private and public environments, and appropriate proportions. Improve the study environment as much as possible with the needs and standards of hoteling. 


\section{REFERENCE}

1. Aris, Bahareh; Karimi Moshavar, Mehrdad, Conceptual Model of Semantic Relationship between Art and Urban Space, Bagh Nazar Scientific Research Journal, Article 1, 15 (6), Pages 5-1 6(2019).

2. Badiei, Shadi; Nasr, Tahereh, Strategies for Architectural Design of Hospital Hospital in Shiraz with Attitude on the Interaction of Environment and Users, html.225_RCEAUD01RCEAUD01-Paper (2015).

3. Alireza; Designing a Model of Iranian Medical Tourism, PhD Thesis, Tehran, School of Medical Management and Information, Iran University of Medical Sciences and Health Services (2008).

4. Khanizad, Shahriar; Hospital Design: Principles and Foundations of Architecture and Interior Design of Hospitals, Translators: Rahimi, Elnaz; Nazarnia, Naghmeh Digital Library of the University of Tehran, Century Architecture, p. 251 (2010).

5. Shamgholi, Gholamreza, Yekta, Hamed, Basic concepts in hospital architecture design, Soroush Danesh, Tehran (2011).

6. Shirzadi, Seyed Majid; Raisi, Pouran; Nasiripour, Amirashkan; Tabibi, Seyed Jamaluddin, Providing a Model for Improving the Quality of Hoteling Services in Iranian Public Hospitals, Health Information Management 14 (3) (2017).

7. Salehi Sedghiani, Jamshid; Qarai, Reza; Assessing the competencies of managers by 360-degree feedback method, Industrial Management Quarterly, No. (9) (2012).

8. Mansouri, Shirvan; Rasouli Dehbakordi, Helgord, The effect of hospital hospitality on medical tourism (case study of Mahabad city), 1.082_ ICRSIEE02-ICRSIE02-Paper (2016).

9. Mohammadifar, Yaghoub, Mir Safdari, Sharareh, Achaemenid Architectural Stylistics, Quarterly Journal of Islamic Iranian City Studies, (2014).

10. Mirzadeh, Sonia and Amir Faraj Elahi Rad, Principles of Hospital HotelDesign with a Tourism Tourism Approach (Case Study of Zahedan), International Conference on Architectural and Urban Engineering, Tehran, Permanent Secretariat of the Conference, (2016), https: //www. civilica .com / Paper-ARCHITECTUREUR01ARCHITECTUREUR01_117.html
11. Neufert, Peter Neufert. Architectural information. Translated by Hossein Mozaffari Tarshizi. Taiba is pious. Iran, Tehran: Azadeh, (2013). 608. ISBN 978-964-501-711-6.

12. Ministry of Health, Treatment and Medical Education - Office of Development of Physical Resources and Civil Affairs, Standard Planning and Design of Safe Hospital, Architecture General Requirements - Hospital Location.

13. Naderi, Ezzatullah; Saif Naraghi, Maryam. Research methods and how to evaluate it in the humanities. Sixth Edition, Tenth Edition, Tehran: Arasbaran (2016).

14.Isaac, StephenGuide to Research and Evaluation in Psychology and Educational Sciences. Translated by Ali Delavar, Tehran: Arasbaran Publishing (2005).

15. Cresol, John W. Planoclark, Wiki. Combined research methods. Translated by Alireza Kiamanesh and Javid Sarai, Second Edition, Tehran: Ayge (2016).

16. Asefzadeh, Saeed; Medical Education and Health Services, Tehran, University Scientific and Cultural Publications (1997).

17.Sedghiani, Ibrahim; Evaluation of Health Care and Hospital Standards, Tehran, Alam va Honar Publications (1997).

18. Asefzadeh, Saeed; Hospital Recognition, Tehran, University Press (1990).

19. Ghaffari; Nasra; Time Management in Production Organization, Quarterly Journal of Management Studies (1993).

20.Sedghiani, Ibrahim; Fesharaki, Nabi Lou, Bahram, A Comparative Study of the Efficiency of the Surgery Department of Urmia Hospitals from the Management Perspective, (1998) 1978-78.

21. Abu Masudi, Abbas; Strategic Planning and its Application in Management; Tehran Spring 82 (2003).

22.Bone SL. Patients' emotional needs. Radiol Technol 2016; 87(6): 716-7.

23. Chris, Brogan, Ideas for Hotels and Hospitality. Brogan, Chris.com.2009

24.Devlin, Ann Sloan, and Cláudia Campos Andrade. "Quality of the hospital experience: Impact of the physical environment." Handbook of environmental psychology and quality of life research. Springer, Cham, 2017. 421-440. 
25.Dexter, Franklin, Rodney D. Traub, and Philip Lebowitz. "Scheduling a delay between different surgeons' cases in the same operating room on the same day using upper prediction bounds for case durations." Anesthesia \& analgesia 92.4 (2001): 943-946.

26. Horowitz, Michael D. "Medical tourismhealth care in the global economy." Physician executive 33.6 (2007): 24.

27.Jabbari, Alireza, et al. "The marketing mix and development of medical tourism in Shiraz." Materia socio-medica 25.1 (2013): 32.

28. Kanich .Donnald "How to the increase in the operating room" Surgical clinic of America 19771996.

29.Kerfoot, Karlene M. "Hospitality and service: Leading real change.” Medsurg Nurs 18.5 (2009): 319-20.
30.Barzegar, M., and M. Moeini Naeini. "The importance of hospitals Hoteling standards and customer satisfaction." (2014).

31.Zeithaml, Valarie A., Leonard L. Berry, and A. Parasuraman. "SERVQUAL: a multiple-item scale for measuring consumer perceptions of service quality." Journal of retailing 64.1 (1988): 12-40.

32.Pati, Debajyoti, et al. "A multidimensional framework for assessing patient room configurations." HERD: Health Environments Research \& Design Journal 2.2 (2009): 88-111.

33. Sacouche, D. A., L. C. Morrone, and J. S. SilvaJúnior. "Impact of ergonomics risk among workers in clothes central distribution service in a hospital.” Work 41. Supplement 1 (2012): 18361840. 